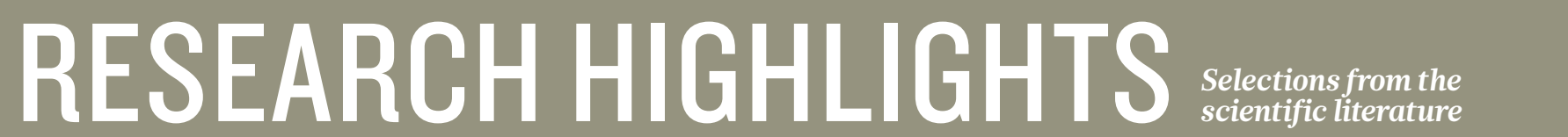

CHEMISTRY

\section{Catalyst makes dyeing greener}

A 'green' polymer could become even greener thanks to a process that eliminates the need for an environmentally damaging dyeing step.

Poly-lactic acid is a polyester manufactured from molecules derived from plants. The dyeing process typically uses large volumes of water and strong alkali, and generates sulphur-contaminated waste water. Patrick McGowan at the University of Leeds, UK, and his colleagues use an aluminium-based catalyst that polymerizes lactic acid or lactides and also carries the dye molecule. This allows the polymerization and dyeing steps to be combined into one, and obviates the need for additional harmful chemicals.

This 'DyeCat' method also reduces production costs and could be used by the textile industry, the authors say.

Angew. Chem. Int. Edn doi:10.1002/anie.201004920 (2010)

PARTICLE PHYSICS

\section{Neutral molecules whirl around}

Particle accelerators typically whip charged particles around using magnetic and electric fields, enabling physicists to investigate high-energy collisions. Peter Zieger of the Fritz Haber Institute in Berlin and his colleagues have

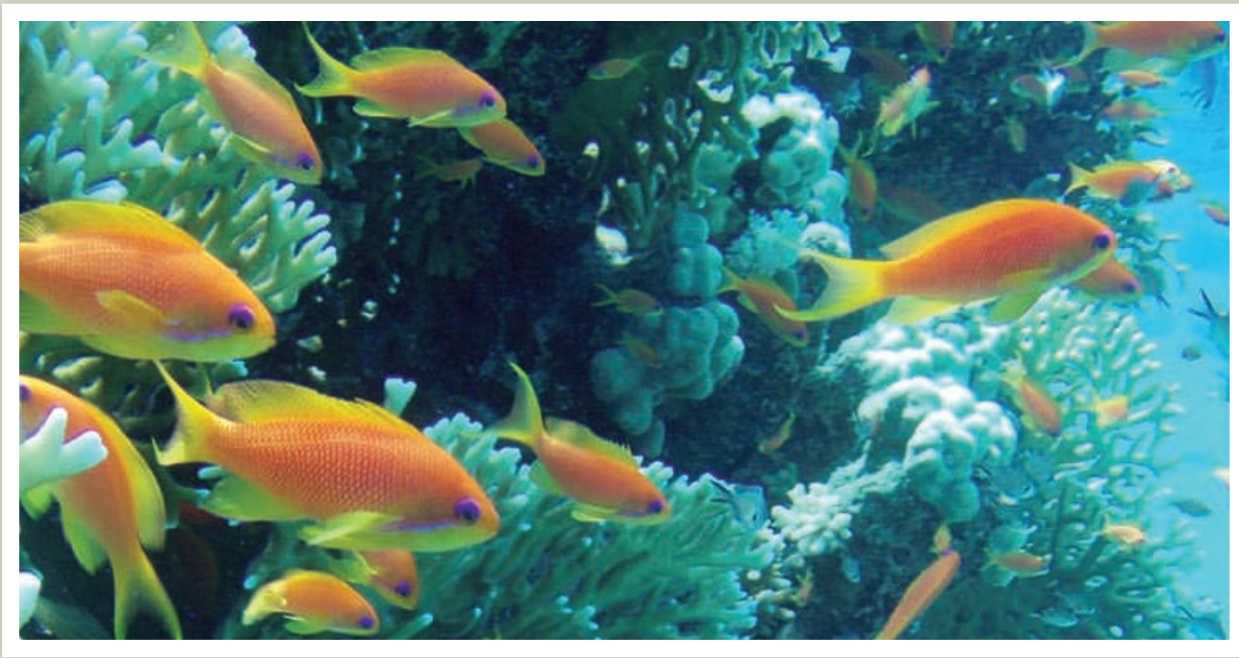

EVOLUTIONARY ECOLOGY

\section{Chasing off biters benefits others}

Behaviour that seemingly contributes to the public good can evolve as a by-product of selfserving actions.

Andrea and Redouan Bshary at the University of Neuchâtel in Switzerland studied a type of blenny fish (Plagiotremus rhinorhynchus) that stealthily bites scalefin anthias (Pseudanthias squamipinnis; pictured) from behind.

Some victims chase the biting blenny after an attack. The authors used Plexiglass plates to mimic chasing or fleeing anthias in the lab, and found that chasing acts as a self-serving punishment, prompting blennies to pursue other individuals in future attacks. In the field, chased blennies were seen biting other prey species, suggesting that chasing also serves a public good.

Moreover, the researchers found that blennies can distinguish between chasers and those that flee or 'free-ride.' They say that free-riders might make themselves easy targets for the blennies, thereby favouring the chasing behaviour. Curr. Biol. doi:10.1016/j.cub.2010.10.027 (2010) built a prototype molecular synchrotron for neutral molecules, a key step towards studying low-energy collisions.

Using specially designed electric fields, the team managed to keep ammonia molecules centred as they whizzed around a 0.5-metrediameter ring (pictured). Varying the strength of the

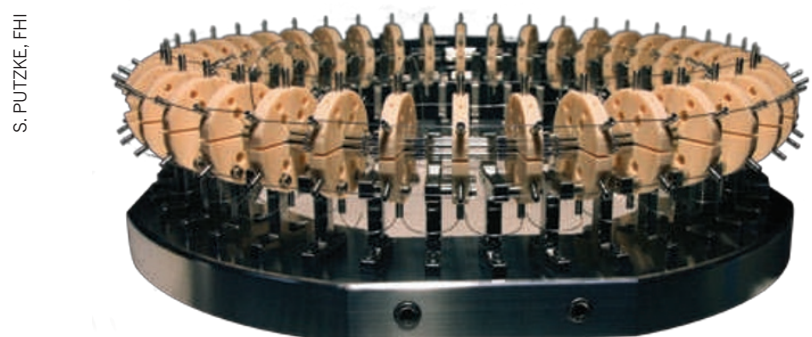

electric fields allowed the group to keep the molecules grouped in 'bunches'. Bunching up the molecules should increase the sensitivity of future collision studies. Phys. Rev. Lett. 105, 173001 (2010)

\section{NEUROBIOLOGY \\ Trimming brain connections}

Immune cells called microglia help to protect the brain after an injury. They may also be involved in pruning the connections, or synapses, between neurons - a key process in learning and memory formation.

Using electron microscopy, Marie-Ëve Tremblay, Rebecca Lowery and Ania Majewska at the University of Rochester in New York imaged mouse brain slices and reconstructed the interactions between microglia and synapses in three dimensions. Most of the microglia were directly adjacent to the synapses, and in particular to dendritic spines - neuronal structures - that were small and were often pruned away later on.

The authors also subjected mice to shifts in visual experience using light deprivation and re-exposure. After this regime, some 